\title{
馬の傳染性賀血の生化學的研究.VIII. 傳貧馬の血湤殘餘窒素に就て
}

岡 村 宏 雄

(束北帝國大學醫學部翳化學教室)

\section{BIOCHEMICAL STUDIES OF INFECTIOISS ANAFMIA IN THE HORSE. VIII. ON THE RESIDUAL NITROGEN OF BLOOD IN THE ANAEMIC HORSE.}

\section{H. OKAMURA,}

(From the Institute of Biochemistry, Faculty of Mexicine.

T'ohoku Inperial Cniversity, Sensai)

\section{緒言}

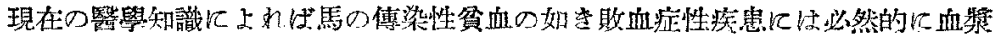

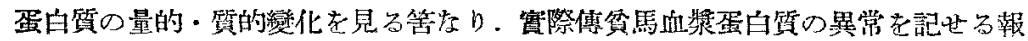

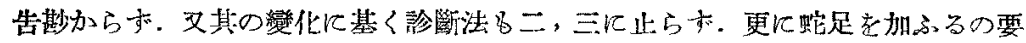

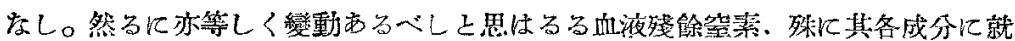

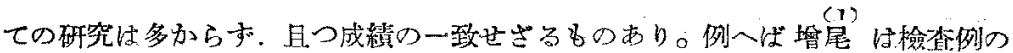

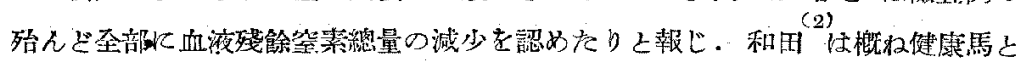

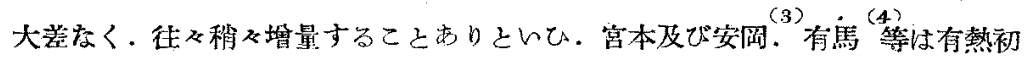

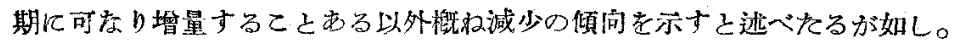

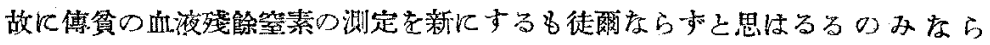

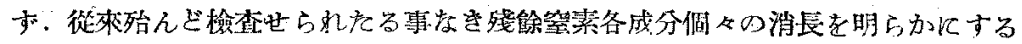

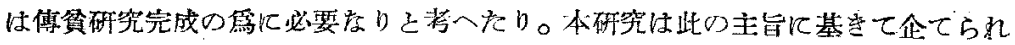

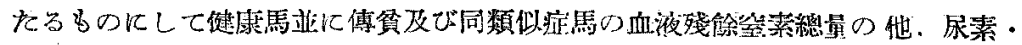
尿酸・クレフナン及びクレアチニンの測定を包念す。アンモニアは血液探集の場 


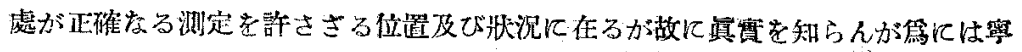
ろ之を省略与名に如か亦之考へをり。

\section{嘪驗方 法}

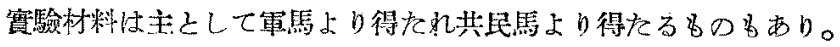

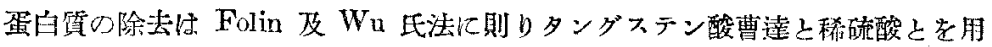

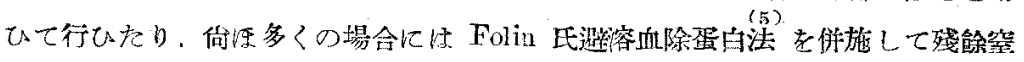

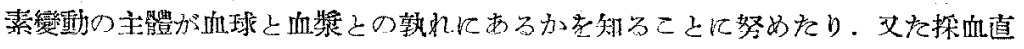

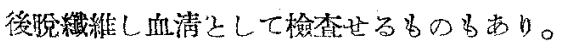

殘餘筑素の總量は慣用の微量かールダールルよりて測定し，尿素空素量はVan

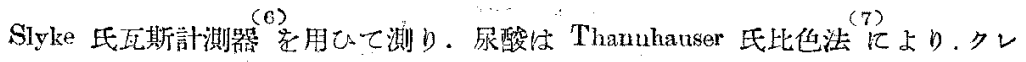
アチン及びクレアチニント公知のFolin 氏法によりて定量せり。因に Squibb ウ

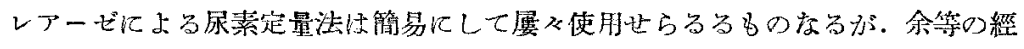

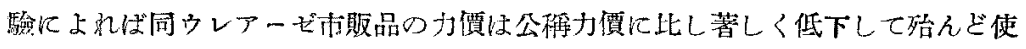

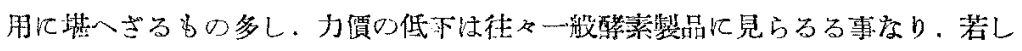

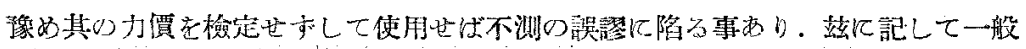
の注意を衡起せんとす。

\section{莌 驗 成 績}

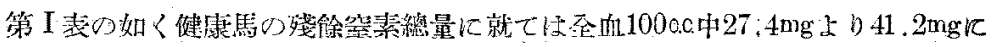

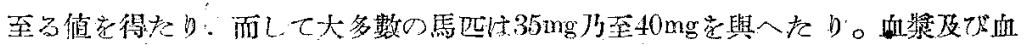

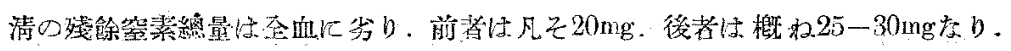

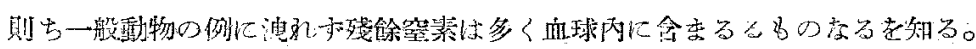

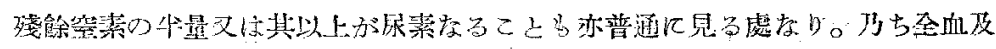

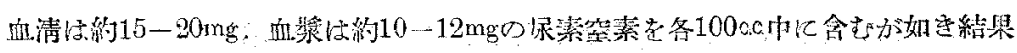

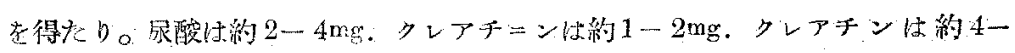

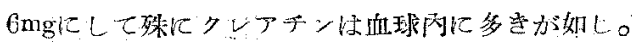

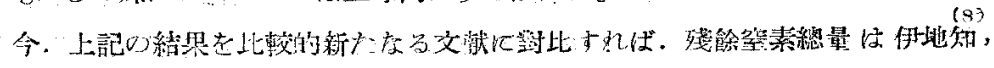




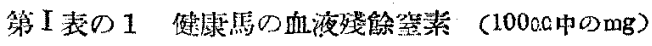

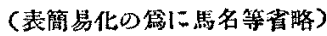

\begin{tabular}{|c|c|c|c|c|c|c|}
\hline \multirow{2}{*}{ 馬番號 } & \multicolumn{4}{|c|}{ 全 } & \multicolumn{2}{|l|}{ 血. } \\
\hline & 殘餆窣素 & 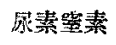 & 㽷 & 酸 & クレアチン & 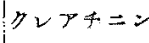 \\
\hline 1 & 30.6 & 15.3 & & 3.8 & - & - \\
\hline 2 & 38.4 & 16.8 & & 4.3 & - & - \\
\hline 3 & 36.4 & 16.6 & & 3.9 & 一 & - \\
\hline 4 & 38.0 & 15.7 & & 4.1 & - & - \\
\hline 5 & 39.1 & 15.8 & & 3.7 & 6.0 & 1.4 \\
\hline$\cdot 6$ & 37.4 & 13.3 & & 3.0 & 5.3 & 1.3 \\
\hline 7 & 35.7 & 15.5 & & $3.5 \cdots$ & 5.1 & 1.3 \\
\hline 8 & 32.4 & 15.0 & & 3.6 & 6.1 & 1.1 \\
\hline 9 & 31.9 & 15.0 & & 4.0 & 3.5 & 1.4 \\
\hline 10 & 27.4 & 14.0 & & 2.4 & 6,4 & 1.6 \\
\hline 11 & 33.2 & 15.1 & & 2.2 & 4.6 & 2.0 \\
\hline 12 & 38.6 & 17.7 & & 2.5 & 5.1 & 1.6 \\
\hline 13 & 35.5 & 17.9 & & 2.3 & 6.5 & 2.9 \\
\hline 14 & 33.5 & 20.3 & & 2.7 & 5.1 & 1.6 \\
\hline 15 & 41.2 & 23.4 & & 3.3 & 6.5 & 1.7 \\
\hline 16 & 37.2 & 21.0 & & 1.0 & 8.6 & 1.5 \\
\hline
\end{tabular}

〔嘴考〕 1 より8まで策馬. 以下民需清の分析。

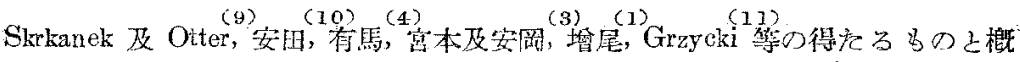

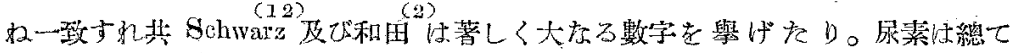

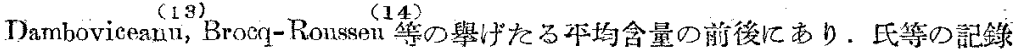

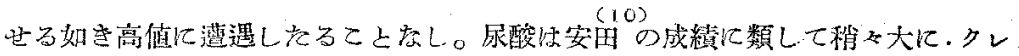

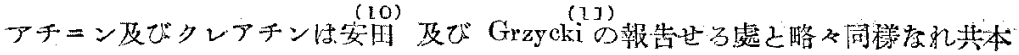
實驗に於て汶僅かに多季傾问を示したり。

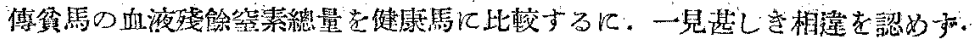


第厂表の 2 （同，崩）

\begin{tabular}{|c|c|c|c|c|c|}
\hline \multirow{2}{*}{ 琴番躆 } & \multicolumn{2}{|c|}{ 血 } & 12 & 满 & \multirow[b]{2}{*}{ クレアチ = } \\
\hline & 残餘啙素 & 庣素紫素 & 尿 “酸 & クレアチン & \\
\hline 1 & 18.2 & 10.9 & 2.4 & - & - \\
\hline 2 & 20.3 & 11.8 & 2.8 & 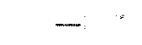 & - \\
\hline 3 & 21.0 & 11.7 & 2.7 & 一 & - \\
\hline 4 & 19.6 & 10.7 & 2.6 & - & - \\
\hline 5 & 17.9 & 10.9 & 2.5 & 2.8 & 0.7 \\
\hline 6 & 18.5 & 9.6 & 1.9 & 2.5 & 0.6 \\
\hline 7 & 19.8 & 11.0 & 2.3 & 40 & 0.8 \\
\hline 8 & 17.6 & 10.5 & 2.2 & 3.5 & 0.7 \\
\hline 9 & 29.3 & 15.4 & 0.6 & 2.6 & 0.9 \\
\hline 10 & $20.1 \div$ & 14.7 & 2.1 & 4.1 & 1.3 \\
\hline 11 & 24.0 & 15.4 & 1.5 & 2.7 & 1.6 \\
\hline 12 & 27.5 & 18.1 & 2.5 & 2.8 & 1.4 \\
\hline 13 & 24.2 & 17.3 & 1.8 & 2.9 & 2.4 \\
\hline 14: & 30.7 & 21.2 & 0.9 & 1.9 & 1.2 \\
\hline 15 & 38.5 & 23.6 & 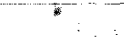 & 2.7 & 1.5 \\
\hline 16 & 30.4 & 24.1 & . & 2.9 & 1.3 \\
\hline
\end{tabular}

〔偖 考】 1 より 8 までは軍馬、以下蛙血清の分析。

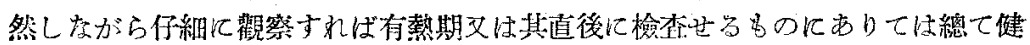

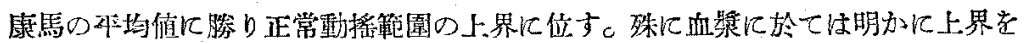
超ゆるものあるを知る。弡熱時に上卓多は通常人類に見る處にして，馬に於て

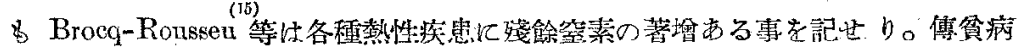

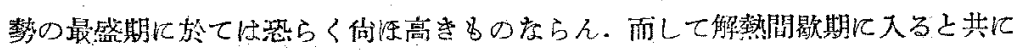

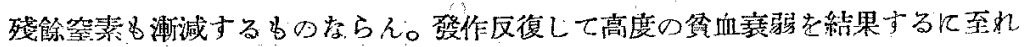
ば更に減少して最後の 2 頭の如く正常以下に下る事あるべし. 本隶殘餘空素の主 源度る血球の減少に由る虐大ならん。間歇期江檢查したるっのは皆慢性陣舊にし 


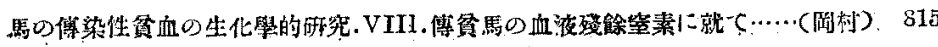

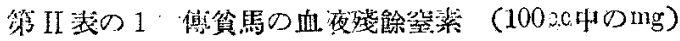

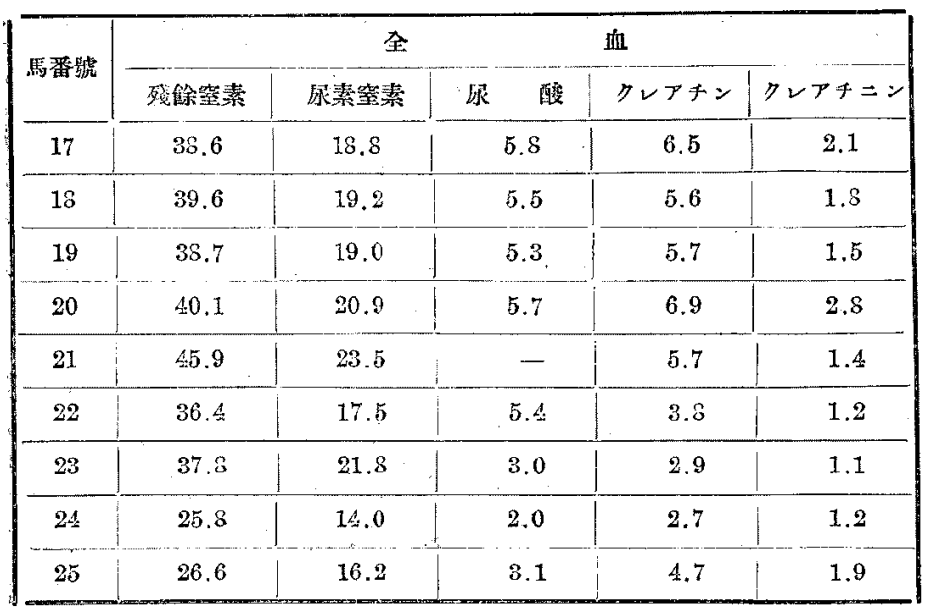

第 $\mathrm{II}$ 表の 2 (前，同)

\begin{tabular}{|c|c|c|c|c|c|c|c|}
\hline \multirow{2}{*}{ 泎番號 } & \multicolumn{2}{|c|}{ 血 } & \multicolumn{2}{|r|}{17} & 清 & \multirow{2}{*}{\multicolumn{2}{|c|}{ クレアキニン }} \\
\hline & 殘餘营素 & 䠌素䇪素 & 㽷 & 酸 & クレアキン & & \\
\hline 17 & 21.2 & 11.6 & & 3.8 & 3.4 & & 1,2 \\
\hline 18 & 24.0 & 12.0 & & 3.2 & 3.6 & ' ' & 1.1 \\
\hline 19 & 23.7 & 12.0 & & 3.2 & 3.6 & & 1.5 \\
\hline 20 & 20.4 & 13.5 & & 3.9 & 3.6 & & 1.2 \\
\hline 21 & 35.3 & $\because 14,1$ & & 1.4 & 4.4 & & 1.3 \\
\hline 22 & $30 . \Omega$ & 21.4 & & 3.6 & 3.1 & & 1.1 \\
\hline 23 & 35.4 & 25.7 & & 2.1 & 2.1 & & 1.0 \\
\hline 24 & 23.5 & 18.6 & & 2.1 & 2.3 & & 1.2 \\
\hline 25 & 24.5 & 12.5 & & 2.8 & 8. 0 & & 1.5 \\
\hline
\end{tabular}

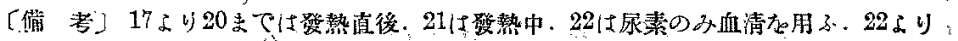
25までは間歇期。23より25までは血清。

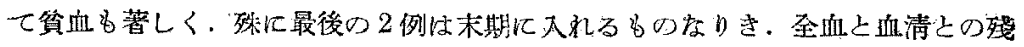
餘空素量が接近せるは蓝し血球心減少に时る處大なるべし。要するに血液殘餘窒 
素總量心有熱期と無熱期とによりて異り．又を發作の回數，經過の長煌，貧血，

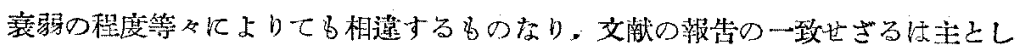
て检查の時期の等しからさるる據ること去ら九と考心。

\section{要 旨}

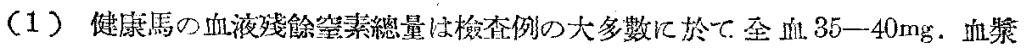
18一-25mg. 血清25一30mgを示したり。總て1000.C中の量なり。上記範国外にある 娄の法此較的少し。

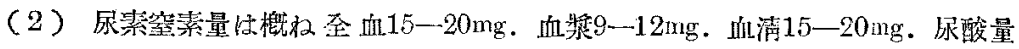

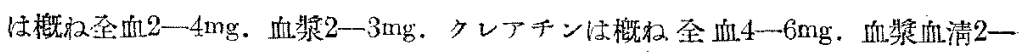

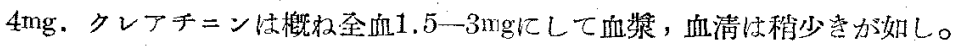

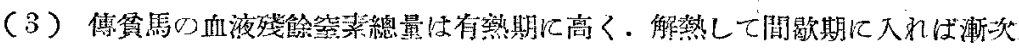

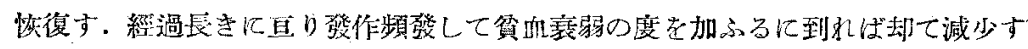

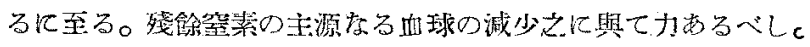

\section{引用文㱆}

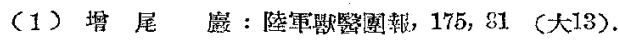

(2) 和田 保: 中央獸醫會锥誌, 44, 475 (炤6).

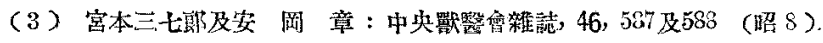

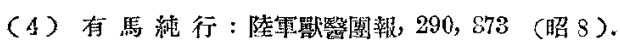

(5) O. Folin : J. Biol. Chen., 86, 176 (1930).

(6) D. D. Vin Slyke \& V. H. Kugel : J. Biol. Chom, 1:2, 489, 499 (19:3).

(7) S. J. Thatnhauser : Lehrbuch d. Stoffwechees u. d. Stoffwechselkrankheiten, 208 (1929).

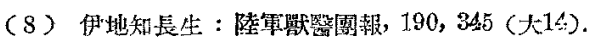

(9) G. Skrkwnek a. K. Otter : Arch. wiss. u. prakt. Tierhlkd., 57, 567 (1920).

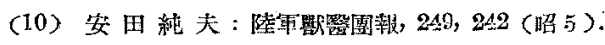

(11) S. Grzycki : C.r. Soc. Biol., 115. 1145 (1934).

(12) K. Schwarz u. H. Hamp : Biochem. Zisehr., 194, $32 \mathrm{~S}$ (192S).

(13) A. Demboviceanu : C.r. Soc. Biot. . 101, 325 (19:9).

(14) D. Brocq-Rousseu, G. Roussel, Gallot : Sang, 3, 175 (1989).

(15) D, Brocqfiousseu, Z, Gruzenske, B,G, Roussel:C. r. Soc. Biol., 104, 852 (1930). 